\title{
LOOKING BEHIND THE PROCESS OF PYROLYSIS IN WASTE MANAGEMENT: QUESTIONS ON THE COMPOSITION AND QUALITY OF END-PRODUCT AND THEIR ANSWERS BY MEAS OF ANALYTICAL CHEMISTRY
}

\author{
Author(s): \\ K. Lányi ${ }^{1}$, E. Molnár ${ }^{1}$, I. Vanó ${ }^{1}$ and P. Korzenszky ${ }^{2}$
}

\author{
Affiliation: \\ ${ }^{1}$ Faculty of Economics, Agricultural and Healthcare Studies, Szent István University \\ Szabadság út 1-3., Szarvas, H-5540, Hungary, Tel.:+36 66561630 \\ ${ }^{2}$ Faculty of Mechanical Engineering, Szent István University, Páter K. út. 1, Gödöllö, H-2100, Hungary
}

\section{Email address:}

lanyi.katalin@gk.szie.hu, Molnar.Erik@gfh.szie.hu, Vano.Imre@gek.szie.hu, Korzenszky.Peter@gek.szie.hu

\begin{abstract}
Recycling technologies gained increased importance in the past decades, since environmental issues and the questions of depleting natural resources. Wastes may be considered as resources of valuable secondary raw materials. This literature review aims at compiling the information available on questions arising from the differences between the chemical composition of traditional fuels and chemical industrial raw materials, together with the analytical chemical methods being able to answer these questions. Issues of technical optimisation, the composition of end-products, and their dependence on the technical parameters of pyrolysis will also be discussed.
\end{abstract}

\section{Keywords}

pyrolysis, waste recycling, secondary raw materials, energy from waste

\section{Introduction}

According to a recent World Bank study (Hoornweg and BhadaTata, 2012) $70 \%$ increase is forecasted in the municipal solid waste globally, from the annual amount of 1.3 billion tonnes presently to an estimated 2.2 billion tons by 2025 . It means also a vast increase in the solid waste management costs from \$205 billion to $\$ 375$ billion in the same term. Developing countries face the greatest challenge, however, the burdens of developed countries will also not decrease.

In the European Union, the 2004/12/EC Directive regulates the issues of packaging and packaging waste. According to this Directive, minimum $60 \%$ of packaging waste shall be recovered or incinerated at waste incineration plants with energy recovery; between $55 \%$ and $80 \%$ of packaging waste shall be recycled. For plastics in packaging waste the minimum recycling target of $22.5 \%$ shall be attained counting exclusively material that is recycled back into plastics. This requirement, together with the ever-growing amounts of solid waste, puts European governments and the environmental technology sector under great pressure in the field of waste recycling.
Due to the previous, the importance of waste management processes will increase that are:

- cost-effective

-the cost-benefit ration can be improved further via producing secondary energy resources or raw materials

- do not produce significant amount of any further waste to be disposed.

Recycling technologies gained increased importance in the past decades, since the environmental issues caused by the still growing amount of wastes cannot be left unconsidered anymore. At the same time, wastes may be considered as resources of valuable secondary raw materials, such as pyrolysis gas (PG) used for energy production and pyrolysis oil that can be used as fuel or as a raw material in the chemical industrial processes. Many researches dealt with the questions of technical optimisation, the composition of end-products, and their dependence on the technical parameters of pyrolysis. However, the environmental consequences of the pyrolysis process itself as well as the compliance of pyrolytic end-products with the regulatory environment have been treated to far below their importance. Moreover, the available scientific methods being able to handle these questions of compliance have not been collected yet.

This literature review aims at compiling, as far as possible, the information available on questions arising from the differences between the chemical composition of traditional fuels and chemical industrial raw materials, together with the analytical chemical methods being able to answer these questions. International standards and legislative prescriptions will be compared to the composition data from literature, as well as, the main problem-areas will be highlighted. Analytical chemical methods suitable to aiming these areas will be collected and presented. Consequences will be drawn in order to support the efforts made for more effective reutilization of wastes of high carbon content, and to highlight the possible traps and difficulties in these processes.

\section{Discussion}

Issues of chemical composition in waste pyrolysis

The dependence of plastic materials' thermal decomposition on the technical parameters have been studied intensively in the 
last decade. Among many other interesting findings, it was determined (Lopez-Urionabarrenechea et al, 2012) that stepwise catalytic pyrolysis can be a useful alternative for recycling mixed plastic waste, however, if PVC is present in the original mixture, it will lead to unfavourable levels of chlorinated organic compounds in the pyrolysis oil, which causes reduced utilisation options as a secondary raw material. Influence of time and temperature on pyrolysis behaviour of plastic wastes was also an intensively studied issue.

A very important technical parameter of pyrolysis is the temperature of reaction. Many investigations dealt with this issue, but the results are not in harmony with each other every time. A Spanish research group found (López et al, 2011a) that by raising pyrolysis temperature, gas yields significantly increase to the detriment of liquid yields. $460^{\circ} \mathrm{C}$ was the lower temperature at which total conversion could be achieved. However, the liquids appeared to be extremely viscous which meant difficulties in handling. $500^{\circ} \mathrm{C}$ seemed to be the optimal temperature for plastic waste pyrolysis, in terms of both conversion and quality of the pyrolysis liquids. Reaction time in the range 15-30 min seemed to be enough to achieve total conversion of the plastic waste. The obtained ratios of different pyrolysis end-products can be seen in the Chart 1

Chart 1. Effect of temperature on pyrolysis yields (wt\%). (López et al, 2011a)

\begin{tabular}{|c|c|c|c|}
\hline Temperature $\left({ }^{\circ} \mathrm{C}\right)$ & Liquids & Gases & Solids \\
\hline 460 & 72.0 & 26.9 & 1.1 \\
\hline 500 & 65.2 & 34.0 & 0.8 \\
\hline 600 & 42.9 & 56.2 & 0.9 \\
\hline
\end{tabular}

In an other research, Chinese researchers (Lin, 2009) found that with a fluidized-bed reactor system, excellent heat and mass transfer, and much less proneness to clogging with molten polymer could be reached at $390{ }^{\circ} \mathrm{C}$. The technology used gave a nearly constant temperature throughout the reactor. The fluidizing cracking reactions were shown to be a useful method for the production of potentially valuable hydrocarbons.

The effect of catalyst can be also a determining factor in obtaining the desired end-products from the pyrolysis process. Researchers showed (López et al. 2011b) that ZSM-5 zeolite is a rather active catalyst for plastic waste pyrolysis; on the one hand, it promotes gas production and causes lower molecular weight and higher ratio of aromatic compounds in the liquids phase even at low temperatures. In this research, Red Mud showed also noticeable activity in plastic waste pyrolysis. However, it needed higher temperatures than zeolite: it showed no activity at $440{ }^{\circ} \mathrm{C}$ while at $500{ }^{\circ} \mathrm{C}$ it increased gas yields, decreased liquids viscosity and promoted liquids aromatization, which are all important factors of further utilization. The comparative results of this research can be seen in the Figure 1.

Without catalysts and at atmospheric pressure the pyrolysis process shows different characteristics (Miskolczi and Nagy, 2012), however, the end-products are similar. But the ratio of different phases, and the composition of the end-products can differ strongly. In the pyrolysis oil, paraffin, olefin, aromatics and naphthenic hydrocarbons were found that made the material favourable for further energetic applications.

Pyrolysis temperature has also significant effect on the composition of the pyrolysis liquids, which is a determining factor in the further utilization options. Owing to this fact, the question of temperature can be a key factor in balancing the costeffectiveness of the pyrolytic waste management processes. Researchers found (Lee and Shin, 2007) that $50{ }^{\circ} \mathrm{C}$ change in the reaction's temperature resulted in significant changes in the composition of pyrolysis oil. Decreasing the temperature from $400{ }^{\circ} \mathrm{C}$ to $350^{\circ}$ caused the amount of aromatic hydrocarbons to decrease slightly, and the open-chain paraffins to decrease significantly. At the same time, the amount of open-chain olefins increased by the decrease in temperature (see figure 1.).

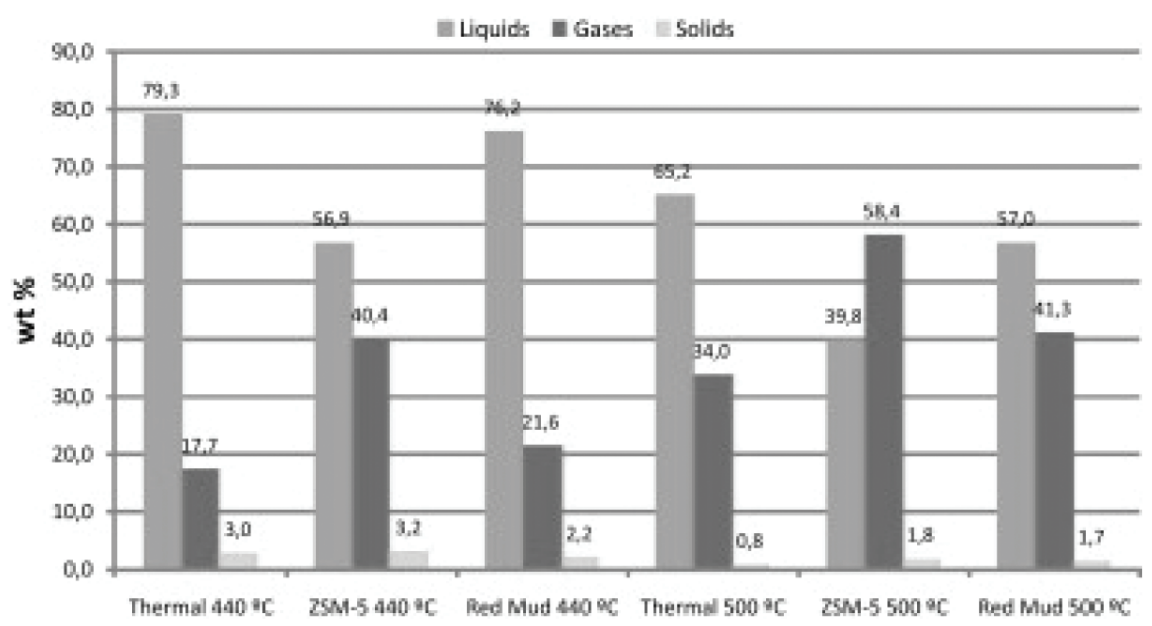

Figure 1. Pyrolysis yields (wt $\%$ ) as a function of temperature and catalyst used. (López et al. 2011b)

Despite the differences in the findings in issues of temperature, or catalyst, researchers generally agree on the significance of the chemical composition of raw waste to be pyrolyzed. Spanish researchers studied intensively (López et al, 2010) the question of pyrolysis raw materials and their effects on the composition of end-product. They studied four different types of incoming wastemixtures rejected from waste management plants: samples 1 and 2 contained more than $90 \mathrm{wt} \%$ packaging plastics while such materials were much less abundant in samples 3 and 4, which contained more than $30 \mathrm{wt} \%$ of materials inappropriate for pyrolysis. Sample 1 contained about $98 \%$ packaging materials while samples 2, 3 and 4 had unusually high film, paper and glass contents. According to their study, the composition of the raw material played a very important role in the distribution and quality of the pyrolysis products. Figure 3. shows the details of the secondary analysis of data from this research. 


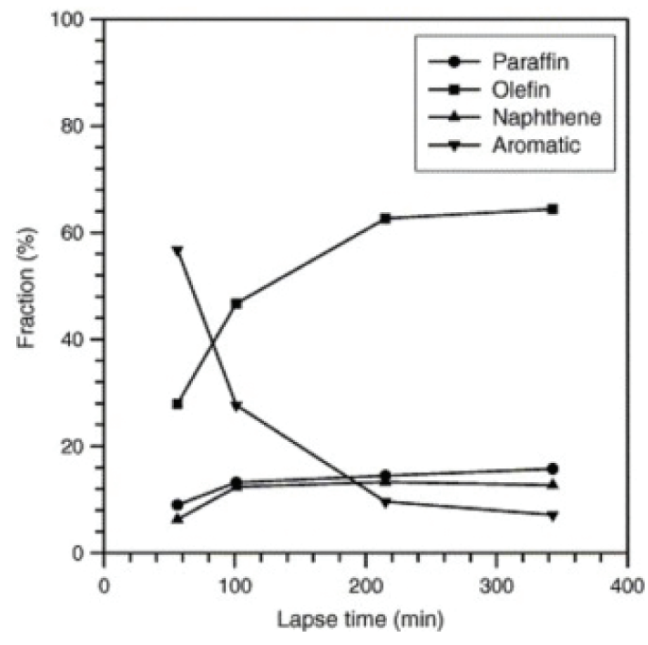

$350{ }^{\circ} \mathrm{C}$

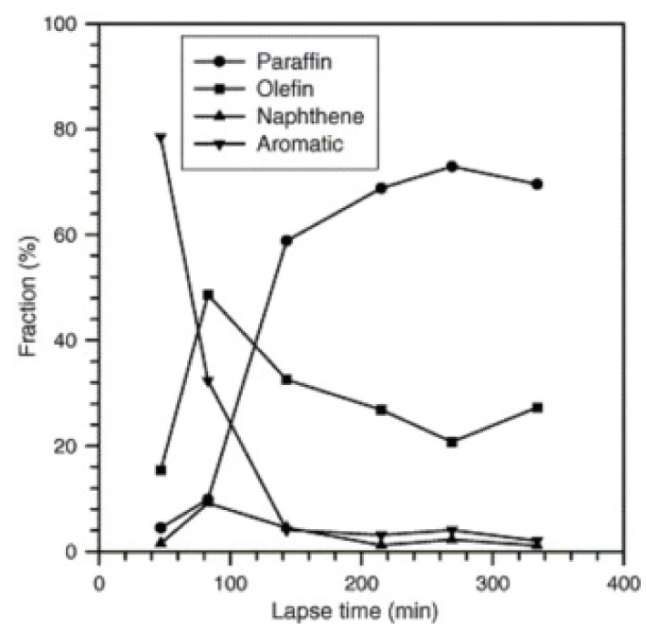

$400{ }^{\circ} \mathrm{C}$

Figure 2. Distribution of compounds of interest in the liquid product of pyrolysis at $350{ }^{\circ} \mathrm{C}$ and $400{ }^{\circ} \mathrm{C}$, respectively

(Lee and Shin, 2007)

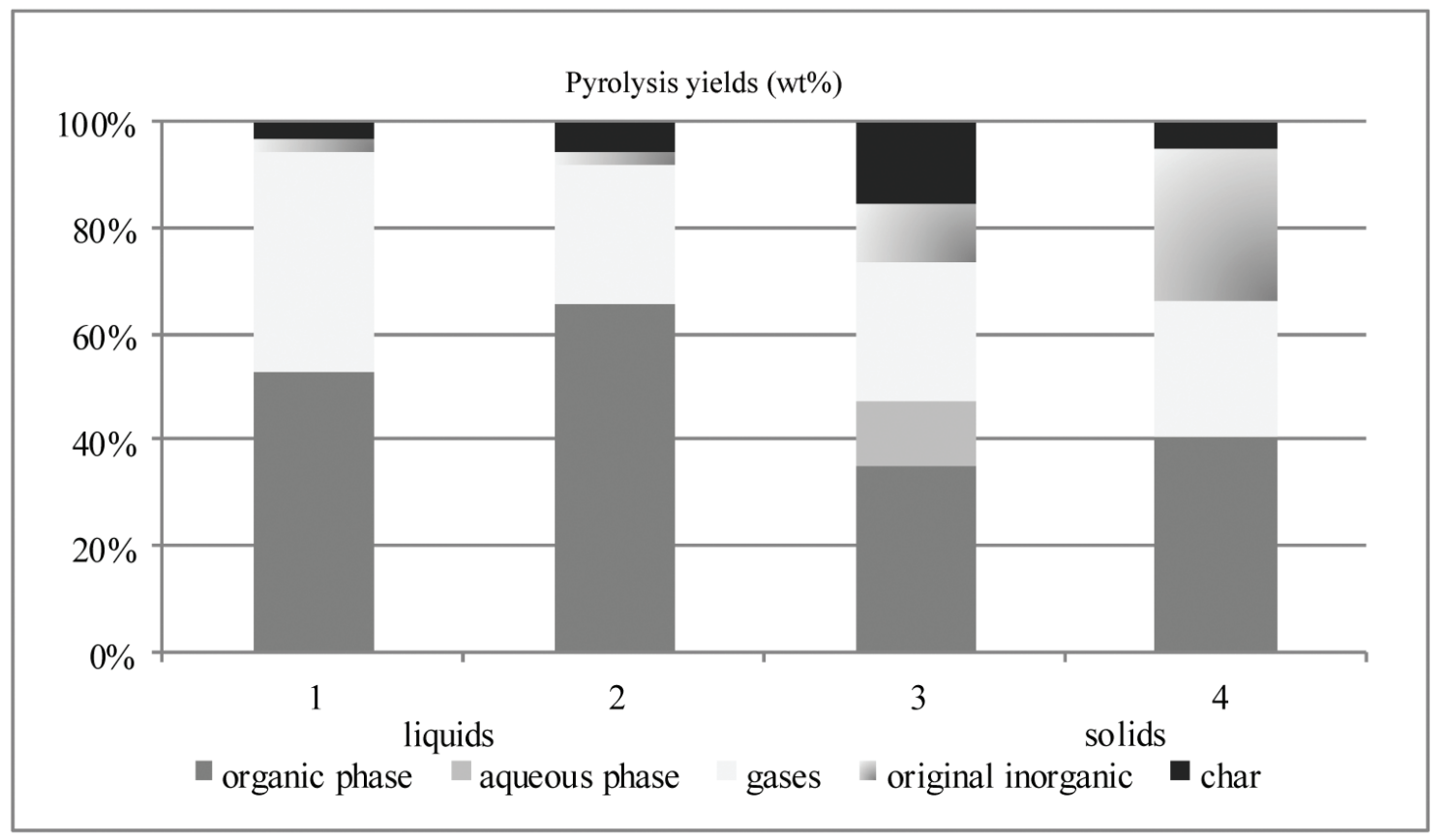

Figure 3. Pyrolysis yields of various waste mixtures (own compilation by López et al. 2010.)

According to the professionals in the field (Hancsók et al, 2013), the materials used as fuels shall comply with the following requirements, as the most important ones:

- good combustion characteristics

- high octane number (petrol), or cetane rating (diesel oils)

- flame temperature is not too high

- lower level of pollutant emission

- very low level of sulphur $(\leq 10 \mathrm{mg} / \mathrm{kg})$

- decreased level of aromatic compounds (petrol: benzene $\leq 1,0$ $\mathrm{v} \%$; total aromatics $\leq 35 \mathrm{v} \%$; diesel oils: polyaromatic hydrocarbons: $\leq 8 \mathrm{v} \%$ )

- decreased level of olefins (petrol: $\leq 18 \mathrm{v} \%$ ).

It can be clearly seen, that the requirements for utilizing the pyrolysis oil as fuel, or as a secondary raw material in the chemical industry (re-polymerisation, etc.) contradict each other significantly.

\section{Analytical chemical procedures}

From the previous, it can be clear that the sulphur content is a key factor in the utilization options of pyrolysis oils. According to the ASTM D 3246-96 standard determination of sulphur in petroleum gas is done by microcoulometric analysis of the product. In addition to the difficulties caused by the complex method requiring high level of expertise and specialised equipment, the detection limit of this method (1-100 ppm) makes it unsuitable for characterizing pyrolysis oils. Several alternatives appeared in the literature, from the rather old idea of using gas chromatograph coupled with flame ionization detector (GC-FID) for determining the sulphur content of petroleum products (Visser et al, 1981), to the most up-to-date approach of X-ray fluorescence (XRF) spectrometry used also by the ASTM D7039-07 standard. 
Amount of aromatic compounds can be also important and shall be investigated carefully. European standard EN 12916:2006 determines the aromatic compound content of petroleum products by high-performance liquid chromatography coupled with refractive index detector (HPLC-RI). This robust method is reliable, fast and relatively easy to carry out. However, the total aromatic content of pyrolysis oils can be out of the range of this method $(7-42 \mathrm{~m} / \mathrm{m} \%)$. Alternative method can be the Fourier transformation infrared spectrometry (FTIR) (Khanmohammadi et al. 2013), or gas chromatograph coupled with mass spectrometer (GC-MS) (Sandercock, Du Pasquier, 2003). However, the detection limits, especially the too high level of analyte to be determined can be a problem also in the case of these alternatives.

\section{Conclusions}

In the recent decades, pyrolysis of plastic wastes proved to be a reliable and useful method for decreasing solid waste instead of landfilling it. However, the fate of end-products from this process rises many questions in the field of chemical composition, which determines further utilisation options, and therefore influences strongly the cost-effectiveness - and thus the sustainability - of the whole process. Although the pyrolysis oil - the most intensively utilised fraction of pyrolysis products - is rather similar in its physical appearance to traditional diesel oils, its chemical composition can differ from it significantly, therefore the simple substitution of diesel oils by pyrolysis oil in machines is questionable. On the other hand, the more and more strong requirements towards technologies resulting in low carbon dioxide loads lead researchers to study other utilisation options for pyrolysis oils not involving combustion: re-polymerisation, or other chemical industrial processes. For these utilisations different chemical composition can be needed that for combustion technologies. The industrial standards for petroleum products in the field of composition analysis have only limited use for analysing pyrolysis oils, due to the differences in chemical composition and the difference in utilisation options. Further investigations in the field of analytical chemical methods will be required in order to promote the technological and economic sustainability of waste pyrolysis processes.

\section{Acknowledgements}

This research was supported by the Hungarian Government and the European Union, with the co-financing of the European Social Fund, within the framework of the TÁMOP-4.2.2.A-11/1/KONV2012-0015 project.

\section{References}

[1] D. Hoornweg and P. Bhada-Tata (2012), What A Waste - A Global Review of Solid Waste Management. World Bank.

[2] A. Lopez-Urionabarrenechea I. de Marco, B.M. Caballero, M.F. Laresgoiti, A. Adrados (2012), Catalytic stepwise pyrolysis of packaging plastic waste. Journal of Analytical and Applied Pyrolysis, Vol. 96. pp. 54-62.

[3] A. López I. de Marco, B.M. Caballero, M.F. Laresgoiti, A. Adrados, A. Aranzabal (2011a), Influence of time and temperature on pyrolysis of plastic wastes in a semi-batch reactor. Chemical Engineering Journal, Vol. 173. pp. 62-71.

[4] Yeuh-Hui Lin (2009), Production of valuable hydrocarbons by catalytic degradation of a mixture of post-consumer plastic waste in a fluidized-bed reactor. Polymer Degradation and Stability, Vol. 94. pp. 1924-1931.

[5] Miskolczi, N. and Nagy R. (2012), Hydrocarbons obtained by waste plastic pyrolysis: Comparative analysis of decomposition described by different kinetic models. Fuel Processing Technology, Vol. 104. pp. 96-104.

[6] A. López I. de Marco, B.M. Caballero, M.F. Laresgoiti, A. Adrados, A. Aranzabal (2011b), Catalytic pyrolysis of plastic wastes with two different types of catalysts: ZSM-5 zeolite and Red Mud. Applied Catalysis B: Environmental, Vol. 104. pp. 211219.

[7] A. López, I. de Marco, B.M. Caballero, M.F. Laresgoiti, A. Adrados (2010), Pyrolysis of municipal plastic wastes: Influence of raw material composition. Waste Management, Vol. 30. pp. 620-627.

[8] Hancsók., J.; Varga Z.; Eller., Z.; Pölczmann, Gy., Kasza., T. (2013), Liquid Alternative Diesel Fuels with High Hydrogen Content. 9th International Colloquium Fuels. January 15-17, 2013, Stuttgart/Ostfildern, Germany.

[9] R. Visser and A Hovestad (1981), Determination of the total sulphur content in gas oils with a flame photometric detector. Journal of Chromatography, Vol. 204. pp. 153-157.

[10] M. Khanmohammadi, A.B. Garmarudi, K. Ghasemi, M. de la Guardia (2013), Quality based classification of gasoline samples by ATR-FTIR spectrometry using spectral feature selection with quadratic discriminant analysis. Fuel, Vol. 111. pp. 96-102.

[11] P.M.L. Sandercock, E. Du Pasquier (2003), Chemical fingerprinting of unevaporated automotive gasoline samples. Forensic Science International, Vol. 134. pp. 1-10.

[12] Korzenszky P., Puskás J., Mozsgai K., Lányi K., Mák Z. (2014), Innovation possibilities of a thermolysis plant to be established in Hungary, 20th International Symposium on Analytical \& Applied Pyrolysis, Birmingham, pp. 115. 